\title{
Common Fixed Point Theorems for OWC Maps in Symmetric Fuzzy Metric Spaces
}

\author{
R. K. Vats \\ Dept of Mathematics \\ NIT Hamirpur (H.P.), India
}

\author{
V. Sihag \\ Dept of Mathematics \\ NIT Hamirpur (H.P.), India
}

\begin{abstract}
The purpose of this paper is to study the existence and uniqueness of common fixed point theorems for owc mappings satisfying a generalized mixed contractive condition of integral type in symmetric GV-fuzzy metric spaces. The perceptions of implicit relation function and control function has been utilized to establish the results. The efforts of this work unify, extend and complement many results existing in recent references and contain every theorem of multivalued self mappings of fuzzy metric space. MSC: 47H10, 54H 25
\end{abstract}

\section{KEYWORDS:}

Common fixed points, weakly, occasionally weakly compatible mappings (owc) and symmetric fuzzy metric spaces.

\section{INTRODUCTION}

Generalization of the Banach contraction mapping principle is one of pivotal results of analysis and has been a heavily investigated branch of research. It is widely considered as the source of metric fixed point theory and the significance lies in its vast applicability in a number of branches of mathematics.

The notion of a fuzzy set, which laid the foundation of fuzzy mathematics, was introduced by Zadeh [1]. Afterward, it was developed extensively by many authors and used in various fields. It is well known that both probabilistic metric spaces and fuzzy metric spaces are generalization of metric spaces. The concept of fuzzy metric spaces has become the area of interest for researcher due to its vast applicability such as to achieve access optimization in information system, history prediction, image filtering and product spaces. Many authors observed that various contracting mapping in metric spaces may be exactly translated in to probabilistic and fuzzy metric spaces endowed with special t-norm such as minimum.

The motivation of introducing the probabilistic metric space is the fact that in many situations the distance between two points is inexact rather than a single real number. But when the uncertainty is due to fuzziness rather than randomness as in the measurement of an ordinary length, it seems that the concept of a fuzzy metric space is more suitable. There are view points of the notion of metric space in fuzzy topology. We can divide them in to the following two groups:
The first group involve those results in which a fuzzy metric on a set $\mathrm{X}$ is treated as a map $\mathrm{d}: \mathrm{X} \times \mathrm{X} \rightarrow \mathrm{R}^{+}$,

where $\mathrm{X}$ represents the totality of all fuzzy points of a set and satisfy some axioms. Thus, in such a approach numerical distances are set up between fuzzy objects. On the other hand Zadeh [1] introduced the concept of fuzzy set as a new way to represent vagueness in everyday life. Since then, many authors following the Banach contraction principle investigated the existence of weaker contractive conditions or extended previous results restively weak hypothesis on metric space. Regarding the theory of fuzzy sets and its applications, have developed a lot of literatures. Especially, Deng [11], Erceg [12], Kaleva and Seikkala [2], Kramosil and Michalek [3] have introduced the concept of fuzzy metric in different ways. Grabiec [6], Kramosil and Michalek [3] have obtained the fuzzy version of Banach contraction principle. Grabiec [6] results for a pair of commuting mappings were further generalized by Subramanyam [7]. Moreover, George and Veeramani [4] modified the concept of fuzzy metric spaces, introduced by Kramosil and Michalek [3]. Further, George and Veeramani [4] introduced the concept of Hausdorff topology on fuzzy metric spaces and shows that every metric induces a fuzzy metric.

In what follows, we collect some relevant definitions, results, examples for our further use.

Definition 1.1 A fuzzy set $\mathrm{A}$ in $\mathrm{X}$ is a function with domain $\mathrm{X}$ and Values in $[0,1]$.

Definition 1.2 A continuous t-norm (in sense of Schweizer and Sklar [5]) is a binary operation T on $[0,1]$ satisfying the following conditions:

(i) $\mathrm{T}$ is a commutative and associative;

(ii) $\mathrm{T}(\mathrm{a}, 1)=\mathrm{a}$ for all $\mathrm{a} \in[0,1]$;

(iii) $\mathrm{T}(\mathrm{a}, \mathrm{b}) \leq \mathrm{T}(\mathrm{c}, \mathrm{d})$ whenever $\mathrm{a} \leq \mathrm{c}$ and $\mathrm{b} \leq \mathrm{d}$

(a, b, c, d $\in[0,1]) ;$

(iv) The mapping $\mathrm{T}:[0,1] \times[0,1] \rightarrow[0,1]$ is continuous.

Remark 1.1 The following are classical example of continuous t-norm

(i) $\mathrm{T}_{\mathrm{M}}(\mathrm{a}, \mathrm{b})=\min \{\mathrm{a}, \mathrm{b}\}$, minimum t-norm. 
(ii) $\mathrm{T}_{\mathrm{H}}(\mathrm{a}, \mathrm{b})= \begin{cases}0 & \text { if } \mathrm{a}=\mathrm{b}=0, \\ \frac{\mathrm{ab}}{\mathrm{a}+\mathrm{b}+\mathrm{ab}} & \text { otherwise, }\end{cases}$

Hamaacher product.

(iii) $\mathrm{T}_{\mathrm{P}}(\mathrm{a}, \mathrm{b})=\mathrm{ab}$, product t-norm.

(iv) $\mathrm{T}_{\mathrm{N}}(\mathrm{a}, \mathrm{b})= \begin{cases}\min \{\mathrm{a}, \mathrm{b}\} & \text { if } \mathrm{a}+\mathrm{b}>1, \\ 0 & \text { otherwise }\end{cases}$

Nilpotent minimum.

(v) $\mathrm{T}_{\mathrm{L}}(\mathrm{a}, \mathrm{b})=\max \{\mathrm{a}+\mathrm{b}-1,0\}$, Lukasiewict t-norm.

(vi) $T_{D}(a, b)= \begin{cases}b & \text { if } a=1, \\ a & \text { if } b=1, \\ 0 & \text { otherwise, }\end{cases}$

Drastic t-norm.

The minimum t-norm is point wise largest t-norm and the drastic t-norm is point wise smallest t-norm; that is, $\mathrm{T}_{\mathrm{M}}(\mathrm{a}, \mathrm{b})$ $\geq \mathrm{T}(\mathrm{a}, \mathrm{b}) \geq \mathrm{T}_{\mathrm{D}}(\mathrm{a}, \mathrm{b})$ for any $\mathrm{t}$-norm $\mathrm{t}$ with $\mathrm{a}, \mathrm{b} \in[0,1]$.

Kramosil and Michalek in [3] generalized the concept of probabilistic metric space given by Menger [8] to the fuzzy framework as follows.

Definition 1.3 A fuzzy metric space (in sense of Kramosil and Michalek [3] ) is a triple (X, M, *), where $X$ is a nonempty set, * is a continuous t-norm and $\mathrm{M}$ is a fuzzy set on $\mathrm{X}^{2} \times[0, \infty)$ such that the following axioms holds:

$$
\begin{aligned}
& (F M-1) M(x, y, 0)=0(x, y \in X) \\
& (F M-2) M(x, y, t)=1 \text { for all } t>0 \text { iff } x=y ; \\
& (F M-3) M(x, y, t)=M(y, x, t)(x, y \in X, t>0) ; \\
& (F M-4) M(x, y, \cdot):[0, \infty) \rightarrow[0,1] \text { is left continuous for } \\
& \quad \text { all } x, y \in X ; \\
& (F M-5) M(x, z, t+s) \geq M(x, y, t) * M(y, z, s) \text { for } \\
& \quad \text { all } x, y, z \in X \text { and } s, t>0 .
\end{aligned}
$$

We will refer to these spaces as KM-fuzzy metric spaces.

Lemma 1.1([6]) For every $x, y \in X$, the mapping $M(x, y, \cdot)$ is nondecreasing on $(0, \infty)$.

In order to introduce an Hausdorff topology on the fuzzy metric spaces, George and Veeramani in [4] modified in a slight but appealing way the notion of fuzzy metric spaces of Kramosil and Michalek.

Definition 1.4 A fuzzy metric space (in sense of George and Veeramani [4]) is a triple (X, M, *), where $\mathrm{X}$ is a nonempty set, * is a continuous t-norm and $M$ is a fuzzy set on $X^{2} \times(0$, $\infty)$ such that the following axioms holds:

$$
\begin{aligned}
& (G V-1) M(x, y, t)>0(x, y \in X) \\
& (G V-2) M(x, y, t)=1 \text { for all } t>0 \text { iff } x=y \\
& (G V-3) M(x, y, t)=M(y, x, t)(x, y \in X, t>0) \\
& (G V-4) M(x, y, \cdot):(0, \infty) \rightarrow(0,1] \text { is continuous for all }
\end{aligned}
$$

$\mathrm{x}, \mathrm{y} \in \mathrm{X}$;

$$
\begin{gathered}
(G V-5) M(x, z, t+s) \geq M(x, y, t) * M(y, z, s) \text { for all } x, \\
y, z \in X \text { and } s, t>0 .
\end{gathered}
$$

Notice that condition $(\mathrm{GV}-5)$ is a fuzzy version of triangular inequality. The value $\mathrm{M}(\mathrm{x}, \mathrm{y}, \mathrm{t})$ can be thought of as degree of nearness between $\mathrm{x}$ and $\mathrm{y}$ with respect to $\mathrm{t}$ and from axiom $(\mathrm{GV}-2)$ we can relate the value 0 and 1 of a fuzzy metric to the notions of $\infty$ and 0 of classical metric respectively.

We will refer to these spaces as GV-fuzzy metric spaces.

Definition 1.5 ([10]) A fuzzy metric $M$ on $X$ is said to be stationary if $M$ does not depend on $t$, i.e., the function $M_{x, y}(t)$ $=\mathrm{M}(\mathrm{x}, \mathrm{y}, \mathrm{t})$ is constant.

We can fuzzify example of metric space into fuzzy metric spaces in a normal way:

Example 1.1([9]) Let $(X, d)$ be metric space and $g: R^{+} \rightarrow R^{+}$ is an increasing continuous function. For $\mathrm{m}>0$, we define the function $\mathrm{M}$ by

(1.1) $\quad M(x, y, t)=\frac{g(t)}{g(t)+m \cdot d(x, y)}$

Then for $a * b=a \cdot b,(X, M, *)$ is a GV-fuzzy metric space on $\mathrm{X}$.

As a particular case if we take $g(t)=t^{\mathrm{n}}$ where $\mathrm{n} \in \mathrm{N}$ and $\mathrm{m}=1$. Then $(1.1)$ becomes

(1.2) $\quad M(x, y, t)=\frac{t^{n}}{t^{n}+d(x, y)}$

Then for $\mathrm{a} * \mathrm{~b}=\mathrm{T}_{\mathrm{M}}(\mathrm{a}, \mathrm{b}),(\mathrm{X}, \mathrm{M}, *)$ is a GV-fuzzy metric space on $\mathrm{X}$.

If we take $n=1$ in (1.2), the well-known fuzzy metric space is obtained.

On the other hand, if we take $g$ as a constant function in (1.1) i.e., $g(t)=k>0$ and $m=1$, we obtain

$$
M(x, y, t)=\frac{k}{k+d(x, y)}
$$

And so $(\mathrm{X}, \mathrm{M}, *)$ is a stationary $\mathrm{GV}$-fuzzy metric space for a * $\mathrm{b}=\mathrm{a} \cdot \mathrm{b}$ but, in general, $\left(X, M, \mathrm{~T}_{\mathrm{M}}\right)$ is not.

Definition 1.6 Let (X, M, *) be a (KM- or GV-) fuzzy metric space. A sequence $\left\{x_{n}\right\}$ is said to be

(i) convergent to a point $x \in X$ (denoted by $\lim _{n \rightarrow \infty} x_{n}$

$$
=x) \text {, if } \lim _{n \rightarrow \infty} M\left(x_{n}, x, t\right)=1 \text {, for all } t>0 .
$$

(ii) a Cauchy sequence if $\lim _{n \rightarrow \infty} M\left(x_{n+p}, x_{n}, t\right)=1$, for all $\mathrm{t}>0$ and $\mathrm{n}, \mathrm{p} \in \mathrm{N}$.

(iii) a complete if every Cauchy sequence in $\mathrm{X}$ is convergent to some point in $\mathrm{X}$.

A map $f: X \rightarrow X$ is called continuos at $x_{0}$ if $\left\{f\left(x_{n}\right)\right\}$ converges to $f\left(x_{0}\right)$ for each $\left\{x_{n}\right\}$ converges to $x_{0}$. 
In 1994, Mishra et. al [13] introduced the concept of compatible mapping in FM-space akin to concept of compatible mapping in metric space as follows:

Definition 1.7 Maps $\mathrm{f}: \mathrm{X} \rightarrow \mathrm{X}$ and $\mathrm{T}: \mathrm{X} \rightarrow \mathrm{B}(\mathrm{X})$ are said to be compatible if $\mathrm{fTx} \in \mathrm{B}(\mathrm{X})$ for each $\mathrm{x} \in \mathrm{X}$ and $\mathrm{M}\left(\mathrm{fT}_{\mathrm{n}}\right.$, $\left.\operatorname{Tfx}_{\mathrm{n}}, \mathrm{t}\right) \rightarrow 1$, whenever $\left\{\mathrm{x}_{\mathrm{n}}\right\}$ is sequence in $X$ such that $\operatorname{Tx}_{\mathrm{n}}$ $\rightarrow\{\mathrm{z}\}\left(\mathrm{M}\left(\mathrm{Tx}_{\mathrm{n}}, \mathrm{z}, \mathrm{t}\right) \rightarrow 1\right)$ and $\mathrm{fx}_{\mathrm{n}} \rightarrow \mathrm{z}$ for some $\mathrm{z} \in \mathrm{X}$

Definition 1.8 Maps $\mathrm{f}: \mathrm{X} \rightarrow \mathrm{X}$ and $\mathrm{T}: \mathrm{X} \rightarrow \mathrm{B}(\mathrm{X})$ are said to be weakly compatible if fTx $\subseteq$ Tfx whenever fx $\in \mathrm{Tx}$.

It is known that a pair $\{f, g\}$ of compatible maps is weakly compatible but converse is not true in general.

Definition 1.9 Let $f, g$ be two self mappings of (X, M, *). A point $\mathrm{x}$ in $\mathrm{X}$ is called a coincidence point of $\mathrm{f}$ and $\mathrm{g}$ iff $\mathrm{fx}=$ gx. We shall call $\mathrm{w}=\mathrm{fx}=\mathrm{gx}$ a point of coincidence of $\mathrm{f}$ and g.

Definition 1.10 Maps $\mathrm{f}: \mathrm{X} \rightarrow \mathrm{X}$ and $\mathrm{T}: \mathrm{X} \rightarrow \mathrm{B}(\mathrm{X})$ are said to be occasionally weakly compatible (owc) if and only if there exist some point $\mathrm{x} \in \mathrm{X}$ such that $\mathrm{fx} \in \mathrm{Tx}$ and $\mathrm{fTx} \subseteq$ Tfx.

Definition 1.11 A symmetric GV-fuzzy metric space is a triple $\left(\mathrm{X}, \mathrm{M},{ }^{*}\right)$, where $\mathrm{X}$ is a nonempty set, * is a continuous t-norm and $M$ is a fuzzy set on $X^{2} \times(0, \infty)$ such that the following axioms holds:

$\mathrm{M}(\mathrm{x}, \mathrm{y}, \mathrm{t})=1$ iff $\mathrm{x}=\mathrm{y}$,

$M(x, y, t)=M(y, x, t)$, for all $x, y \in X, t>0$.

A set $X$ together with a symmetric fuzzy metric $M$ is called symmetric fuzzy metric space.

Lemma 1.2 Let $X$ be a set, and $f$, g owc self mapping of $X$. If $f$ and $g$ have unique point of coincidence, $w=f x=g x$, then $\mathrm{w}$ is a unique common fixed point of $\mathrm{f}$ and $\mathrm{g}$.

Lemma 1.3([7]) If for all $x, y \in X, t>0$ with positive number $\mathrm{k} \in(0,1)$ and $\mathrm{M}(\mathrm{x}, \mathrm{y}, \mathrm{kt}) \geq \mathrm{M}(\mathrm{x}, \mathrm{y}, \mathrm{t})$ then $\mathrm{x}=\mathrm{y}$.

In 2002 Branciari [20] analyzed the existence of fixed point for mapping $\mathrm{f}$ defined on complete metric space $(\mathrm{X}, \mathrm{d})$ satisfying a contractive condition of integral type. (see the following theorem).

Theorem 1.1 Let $(X, d)$ be a complete metric space, $\alpha \in(0$, 1) and $f: X \rightarrow X$ be a mapping such that for each $x, y \in X$, $\int_{0}^{\mathrm{d}(\mathrm{fx}, \mathrm{fy})} \phi(\mathrm{t}) \mathrm{dt} \leq \int_{0}^{\mathrm{d}(\mathrm{x}, \mathrm{y})} \phi(\mathrm{t}) \mathrm{dt}$, where $\phi:[0,+\infty) \rightarrow[0$, $+\infty)$ is Lebesgue-integrable mapping which is summable ( i.e., with finite integral) on each compact subset of $[0,+\infty)$, nonnegative, and such that for each $\varepsilon>0, \int_{0}^{\varepsilon} \phi(\mathrm{t})>0$; then $\mathrm{f}$ has a unique fixed point $\mathrm{a} \in \mathrm{X}$ such that for each $\mathrm{x} \in \mathrm{X}$, $\lim _{n \rightarrow \infty} f^{n} x=a$.

The aim of this paper is to obtain fixed point theorems for maps involving hybrid pairs of single valued and multivalued owc maps satisfying a generalized mixed contractive condition of integral type in the frame work of symmetric fuzzy metric space.

Lemma 1.3( Lebesgue Dominated Convergence Theorem) If a sequence $\left\{\mathrm{f}_{\mathrm{n}}\right\}$ of Lebesgue measurable functions converges almost everywhere to $\mathrm{f}$ and if there exist an integrable function $\geq 0$ such that $\left|f_{n}(x)\right| \leq g(x)$ for every $n$, then $|f(x)| \leq g(x)$ and $\lim _{n \rightarrow \infty} \int f_{n}(x) d x=\int f(x) d x$.

We will use the following notations, throughout this paper, where $(\mathrm{X}, \mathrm{M}, *)$ is a symmetric fuzzy metric space, and $B(X)$ is the class of all nonempty, bounded subset of $X$.

Assume that $\mathrm{F}:[0,1] \rightarrow[0,1]$ satisfies the following.

(i) $\mathrm{F}(1)=1$ and $\mathrm{F}(\mathrm{t}) \geq \mathrm{t}$ for each $\mathrm{t} \in(0,1)$.

(ii) $\mathrm{F}$ is non-decreasing on $[0,1]$.

Define, $\Gamma[0,1]=\{\mathrm{F}$ : F satisfies (i)-(ii) above $\}$.

Let $\psi:[0,1] \rightarrow \mathrm{R}$ satisfies the following

(iii) $\psi(\mathrm{t})>\mathrm{t}$ for each $\mathrm{t} \in(0,1)$.

(iv) $\psi$ is non-decreasing and left continuous.

Define, $\Psi(0,1]=\{\psi: \psi$ satisfies (iii)-(iv) above $\}$.

\section{COMMON FIXED POINT THEOREM}

In this section, we prove fixed point theorems for hybrid pair of single valued and multivalued maps satisfying mixed contractive condition of integral type in the frame work of symmetric fuzzy metric spaces.

Theorem 2.1 Let $f$, $g$ be self mapping of a symmetric GVfuzzy metric space $(\mathrm{X}, \mathrm{M}, *)$ and $\mathrm{T}, \mathrm{S}$ be mappings from $\mathrm{X}$ into $\mathrm{B}(\mathrm{X})$ such that the pairs $\{\mathrm{f}, \mathrm{T}\}$ and $\{\mathrm{g}, \mathrm{S}\}$ are occasionally weakly compatible, satisfying

(1) $\int_{0}^{\mathrm{F}(\mathrm{M}(\mathrm{Tx}, \mathrm{Sy}, \mathrm{t}))} \phi(\mathrm{s}) \mathrm{ds} \geq \int_{0}^{\psi(\mathrm{F}(\mathrm{m}(\mathrm{x}, \mathrm{y}, \mathrm{t})))} \phi(\mathrm{s}) \mathrm{ds}$

for each $\mathrm{x}, \mathrm{y} \in X$ and $\mathrm{t}>0$, for which $\mathrm{fx} \neq \mathrm{gy}$, where

(2) $\mathrm{m}(\mathrm{x}, \mathrm{y})=\mathrm{p} \mathrm{M}(\mathrm{gy}, \mathrm{Ty}, \mathrm{t}) \frac{1-\mathrm{M}(\mathrm{fx}, \mathrm{Tx}, \mathrm{t})}{1-\mathrm{M}(\mathrm{fx}, \mathrm{gy}, \mathrm{t})}$

$+\min \{M(f x, g y, t), M(f x, T x, t), M(g y, S y, t)$,

$M(f x, S y, t), M(g y, T x, t)\}$,

where $0<\mathrm{p}<1$, then $\mathrm{f}, \mathrm{g}$, $\mathrm{T}$ and $\mathrm{S}$ have a unique common fixed point.

Proof - Since the pairs $\{\mathrm{f}, \mathrm{T}\}$ and $\{\mathrm{g}, \mathrm{S}\}$ are occasionally weakly compatible, therefore by definition, there exist $\mathrm{x}, \mathrm{y}$ in $\mathrm{X}$ such that $\mathrm{fx} \in \mathrm{Tx}, \mathrm{gy} \in \mathrm{Sy}, \mathrm{fTx} \subseteq \mathrm{Tfx}$ and $\mathrm{gSy} \subseteq \mathrm{Sgy}$. Also $M\left(f^{2} x, g^{2} y, t\right) \geq M(T f x$, Sgy, $t)$. We first show that $f x=g y$, if not then (2) implies

$$
\text { (3) } \begin{aligned}
& m(f x, g y, t)=p M\left(g^{2} y, T g y, t\right) \frac{1-M\left(f^{2} x, T f x, t\right)}{1-M\left(f^{2} x, g^{2} y, t\right)} \\
&+ \min \left\{M\left(f^{2} x, g^{2} y, t\right), M\left(f^{2} x, T f x, t\right),\right. \\
&\left.M\left(g^{2} y, S g y, t\right), M\left(f^{2} x, S g y, t\right), M\left(g^{2} y, T f x, t\right)\right\} \\
& \geq M(T f x, S g y, t)
\end{aligned}
$$

Now, we have by use of (3) in (1) that

$$
\begin{aligned}
\int_{0}^{\mathrm{F}(\mathrm{M}(\mathrm{Tfx}, \mathrm{Sgy}, \mathrm{t}))} \phi(\mathrm{s}) \mathrm{ds} & \geq \int_{0}^{\psi(\mathrm{F}(\mathrm{m}(\mathrm{fx}, \mathrm{gy}, \mathrm{t})))} \phi(\mathrm{s}) \mathrm{ds} \\
& \geq \int_{0}^{\psi(\mathrm{F}(\mathrm{M}(\mathrm{Tfx}, \mathrm{Sgy}, \mathrm{t})))} \phi(\mathrm{s}) \mathrm{ds}
\end{aligned}
$$




$$
>\int_{0}^{(\mathrm{F}(\mathrm{M}(\mathrm{Tfx}, \mathrm{Sgy}, \mathrm{t})))} \phi(\mathrm{s}) \mathrm{ds}
$$

It leads to a contradiction and hence, $g y=f x$. Obviously, $M\left(f x, g^{2} y, t\right) \geq M(T x, S f x, t)$.

Next, we claim that $x=f x$, if not then consider by (2)

$$
\begin{aligned}
& \mathrm{m}(\mathrm{x}, \mathrm{fx}, \mathrm{t})=\mathrm{p} \mathrm{M}(\mathrm{gfx}, \mathrm{Tfx}, \mathrm{t}) \frac{1-M(f \mathrm{f}, \mathrm{Tx}, \mathrm{t})}{1-M(f x, g f x, t)} \\
&+\min \left\{M\left(f x, g^{2} y, t\right), M(f x, T x, t), M\left(g^{2} y, S g y, t\right),\right. \\
&\left.M(g y, S g y, t), M\left(g^{2} y, T x, t\right)\right\} \\
& \geq M(T x, S f x, t)
\end{aligned}
$$

Using (5), we have by (1),

$$
\begin{aligned}
\int_{0}^{\mathrm{F}(\mathrm{M}(\mathrm{Tx}, \mathrm{Sfx}, \mathrm{t}))} \phi(\mathrm{s}) \mathrm{ds} & \geq \int_{0}^{\psi(\mathrm{F}(\mathrm{m}(\mathrm{x}, \mathrm{fx}, \mathrm{t})))} \phi(\mathrm{s}) \mathrm{ds} \\
& \geq \int_{0}^{\psi(\mathrm{F}(\mathrm{M}(\mathrm{Tx}, \mathrm{Sf} x, \mathrm{t})))} \phi(\mathrm{s}) \mathrm{ds} \\
& >\int_{0}^{(\mathrm{F}(\mathrm{M}(\mathrm{Tx}, \mathrm{Sf}, \mathrm{t})))} \phi(\mathrm{s}) \mathrm{ds}
\end{aligned}
$$

Which is again a contradiction and the claim follows. On the same account, we can prove $\mathrm{y}=\mathrm{gy}$.

Thus $\mathrm{f}, \mathrm{g}, \mathrm{T}$ and $\mathrm{S}$ have a common fixed point and uniqueness follows easily from (1).

Corollary 2.1 The theorem (2.1), will remain proved if the contractive condition (2) is replaced by any of following

(i) $\mathrm{m}(\mathrm{x}, \mathrm{y}, \mathrm{t})=\mathrm{p} \mathrm{M}(\mathrm{gy}, \mathrm{Ty}, \mathrm{t}) \frac{1-\mathrm{M}(\mathrm{fx}, \mathrm{Tx}, \mathrm{t})}{1-\mathrm{M}(\mathrm{fx}, \mathrm{gy}, \mathrm{t})}$

$+h \min \{M(f x, g y, t), M(f x, T x, t), M(g y, S y, t)$,

$[\mathrm{M}(\mathrm{fx}, \mathrm{Sy}, \mathrm{t}) * \mathrm{M}(\mathrm{gy}, \mathrm{Tx}, \mathrm{t})]\}$, where $0 \leq \mathrm{h}<1$.

(ii) $\mathrm{m}(\mathrm{x}, \mathrm{y}, \mathrm{t})=\mathrm{p} \mathrm{M}(\mathrm{gy}, \mathrm{Ty}, \mathrm{t}) \frac{1-\mathrm{M}(\mathrm{fx}, \mathrm{Tx}, \mathrm{t})}{1-\mathrm{M}(\mathrm{fx}, \mathrm{gy}, \mathrm{t})}$

$+\alpha M(f x, g y, t) * \beta\{M(f x, T x, t) * M(g y, S y, t)\}$

$* \gamma \min \{\mathrm{M}(\mathrm{fx}, \mathrm{gy}, \mathrm{t}), \mathrm{M}(\mathrm{fx}, \mathrm{Sy}, \mathrm{t}), \mathrm{M}(\mathrm{gy}, \mathrm{Tx}, \mathrm{t})\}$,

where $\alpha, \beta, \gamma>0$ and $\alpha+\beta+\gamma=0$.

(iii) $\quad \mathrm{m}(\mathrm{x}, \mathrm{y}, \mathrm{t})=\mathrm{p} \mathrm{M}(\mathrm{gy}, \mathrm{Ty}, \mathrm{t}) \frac{1-\mathrm{M}(\mathrm{fx}, \mathrm{Tx}, \mathrm{t})}{1-\mathrm{M}(\mathrm{fx}, \mathrm{gy}, \mathrm{t})}$

$+(\alpha+\beta+\gamma) \min \{\mathrm{M}(\mathrm{fx}, \mathrm{gy}, \mathrm{t}), \mathrm{M}(\mathrm{fx}, \mathrm{Tx}, \mathrm{t})$,

$M(g y, S y, t), M(f x, S y, t), M(g y, T x, t)\}$.

(iv) $m(x, y, t)=p M(f y, T y, t) \frac{1-M(f x, T x, t)}{1-M(f x, f y, t)}$

$+\min \{M(f x, f y, t),[M(f x, T x, t) * M(f y, T y, t)]$,

$\left.\frac{1}{2}[M(f x, T y, t) * M(f y, T x, t)]\right\}$,

where we have assumed $\mathrm{f}=\mathrm{g}$ and $\mathrm{T}=\mathrm{S}$. As all above cases are special cases of condition (2.2), result follows from theorem (2.1).

Theorem 2.3 Let $f$, $g$ be self mapping of a symmetric GVfuzzy metric space $(\mathrm{X}, \mathrm{M}, *)$ and $\mathrm{T}, \mathrm{S}$ be mappings from $\mathrm{X}$ into $\mathrm{B}(\mathrm{X})$ such that the pairs $\{\mathrm{f}, \mathrm{T}\}$ and $\{\mathrm{g}, \mathrm{S}\}$ are occasionally weakly compatible, satisfying
(7) $\quad \int_{0}^{\mathrm{F}\left((\mathrm{M}(\mathrm{Tx}, \mathrm{Sy}, \mathrm{t}))^{\mathrm{p}}\right)} \phi(\mathrm{s}) \mathrm{ds} \geq \int_{0}^{\psi\left(\mathrm{F}\left(\mathrm{m}_{\mathrm{p}}(\mathrm{x}, \mathrm{y}, \mathrm{t})\right)\right)} \quad \phi(\mathrm{s}) \mathrm{ds}$

for each $\mathrm{x}, \mathrm{y} \in \mathrm{X}$, for which $\mathrm{fx} \neq \mathrm{gy}$, where

$$
\begin{aligned}
& \mathrm{m}_{\mathrm{p}}(\mathrm{x}, \mathrm{y})=\mathrm{q}(\mathrm{M}(\mathrm{gy}, \mathrm{Ty}, \mathrm{t}))^{\mathrm{p}} \frac{1-(\mathrm{M}(\mathrm{fx}, \mathrm{Tx}, \mathrm{t}))^{\mathrm{p}}}{1-(\mathrm{M}(\mathrm{fx}, \mathrm{gy}, \mathrm{t}))^{\mathrm{p}}} \\
&+\alpha(\mathrm{M}(\mathrm{Tx}, \mathrm{gy}, \mathrm{t}))^{\mathrm{p}} \\
&+(1-\alpha) \max \left\{(\mathrm{M}(\mathrm{fx}, \mathrm{Tx}, \mathrm{t}))^{\mathrm{p}},(\mathrm{M}(\mathrm{gy}, \mathrm{Sy}, \mathrm{t}))^{\mathrm{p}},\right. \\
& \\
&(\mathrm{M}(\mathrm{fx}, \mathrm{Tx}, \mathrm{t}))^{\mathrm{p} / 2}(\mathrm{M}(\mathrm{gy}, \mathrm{Tx}, \mathrm{t}))^{\mathrm{p} / 2}, \\
&\left.(\mathrm{M}(\mathrm{gy}, \mathrm{Tx}, \mathrm{t}))^{\mathrm{p} / 2}(\mathrm{M}(\mathrm{fx}, \mathrm{Sy}, \mathrm{t}))^{\mathrm{p} / 2}\right\},
\end{aligned}
$$

Where $0<\mathrm{q}<1,0<\mathrm{a} \leq 1$, and $\mathrm{p} \geq 1$, then $\mathrm{f}, \mathrm{g}, \mathrm{T}$ and $\mathrm{S}$ have a unique common fixed point.

Proof - The result follows immediately on the same pattern as in theorem (2.1).

Define $G=\left\{g: R^{5} \rightarrow R^{5}\right\}$ such that

$\left(\mathrm{g}_{1}\right) \mathrm{g}$ is non-decreasing in the $4^{\text {th }}$ and $5^{\text {th }}$ variables,

$\left(\mathrm{g}_{2}\right)$ if $\mathrm{u} \in \mathrm{R}^{+}$is such that

$$
\begin{aligned}
\mathrm{u} & \leq \mathrm{g}(\mathrm{u}, 1,1, \mathrm{u}, \mathrm{u}) \text { or } \mathrm{u} \leq \mathrm{g}(1, \mathrm{u}, 1, \mathrm{u}, \mathrm{u}) \\
\text { or } \mathrm{u} & \leq \mathrm{g}(1,1, \mathrm{u}, \mathrm{u}, \mathrm{u}), \text { then } \mathrm{u}=1 .
\end{aligned}
$$

Theorem 2.4 Let $\mathrm{f}$, $\mathrm{g}$ be self mapping of a symmetric Gvfuzzy metric space $(\mathrm{X}, \mathrm{M}, *)$ and $\mathrm{T}, \mathrm{S}$ be mappings from $\mathrm{X}$ into $\mathrm{B}(\mathrm{X})$ such that the pairs $\{\mathrm{f}, \mathrm{T}\}$ and $\{\mathrm{g}, \mathrm{S}\}$ are occasionally weakly compatible, satisfying

(9) $\int_{0}^{\mathrm{F}(M(\mathrm{Tx}, \mathrm{Sy}, \mathrm{t}))} \phi(\mathrm{s}) \mathrm{ds} \geq \int_{0}^{\mathrm{m}(\mathrm{x}, \mathrm{y}, \mathrm{t})} \phi(\mathrm{s}) \mathrm{d} \mathrm{s}$

for each $\mathrm{x}, \mathrm{y} \in \mathrm{X}$, for which $\mathrm{fx} \neq \mathrm{gy}$, where

(10) $m(x, y, t)=p M(g y, T y, t) \frac{1-M(f x, T x, t)}{1-M(f x, g y, t)}$

$$
+\mathrm{g}\{\mathrm{F}(\mathrm{M}(\mathrm{fx}, \mathrm{gy}, \mathrm{t})), \mathrm{F}(\mathrm{M}(\mathrm{fx}, \mathrm{Tx}, \mathrm{t})),
$$

$\mathrm{F}(\mathrm{M}(\mathrm{gy}, \mathrm{Sy}, \mathrm{t})), \mathrm{F}(\mathrm{M}(\mathrm{fx}, \mathrm{Sy}, \mathrm{t})), \mathrm{F}(\mathrm{M}(\mathrm{gy}, \mathrm{Tx}, \mathrm{t}))\}$

where $0<\mathrm{p}<1$, then $\mathrm{f}, \mathrm{g}$, $\mathrm{T}$ and $\mathrm{S}$ have a unique common fixed point.

Proof - Since the pairs $\{\mathrm{f}, \mathrm{T}\}$ and $\{\mathrm{g}, \mathrm{S}\}$ are occasionally weakly compatible, therefore by definition, there exist $\mathrm{x}, \mathrm{y}$ in $\mathrm{X}$ such that $\mathrm{fx} \in \mathrm{Tx}$, gy $\in \mathrm{Sy}, \mathrm{fTx} \subseteq \mathrm{Tfx}$ and gSy $\subseteq \mathrm{Sgy}$. Also $M(f x, g y, t) \geq M(T x, S y, t)$. First, we show that $g y=f x$. Suppose not, then by (10), we have

$$
\begin{array}{r}
\mathrm{m}(\mathrm{x}, \mathrm{y}, \mathrm{t})=\mathrm{g}\{\mathrm{F}(\mathrm{M}(\mathrm{f} \mathrm{x}, \mathrm{gy}, \mathrm{t})), 1,1, \mathrm{~F}(\mathrm{M}(\mathrm{fx}, \mathrm{Sy}, \mathrm{t})), \\
\mathrm{F}(\mathrm{M}(\mathrm{gy}, \mathrm{Tx}, \mathrm{t}))\} \\
\geq \mathrm{g}\{\mathrm{F}(\mathrm{M}(\mathrm{Tx}, \mathrm{Sy}, \mathrm{t})), 1,1, \mathrm{~F}(\mathrm{M}(\mathrm{Tx}, \mathrm{Sy}, \mathrm{t})), \\
\mathrm{F}(\mathrm{M}(\mathrm{Sy}, \mathrm{Tx}, \mathrm{t}))\} .
\end{array}
$$

By $\left(g_{2}\right)$, we get $M(x, y, t)=1$, with this, (9) implies that

$\int_{0}^{\mathrm{F}(M(\mathrm{Tx}, \mathrm{Sy}, \mathrm{t}))} \phi(\mathrm{s}) \mathrm{ds} \geq 1$, implies that $\mathrm{M}(\mathrm{Tx}, \mathrm{Sy}, \mathrm{t})=1$, further implies that $\mathrm{M}(\mathrm{fx}, \mathrm{gy}, 1)=1$. Which is a contradiction, hence claim follows i.e., $f x=g y$. Also $M\left(f x, f^{2} x, t\right) \geq M(T f x$, Sy, $t$ ). Next we claim that, $f x=f^{2} x$ if not, then by (10), we have

$$
\mathrm{m}(\mathrm{f} x, \mathrm{y}, \mathrm{t})=\mathrm{g}\left\{\mathrm{F}\left(\mathrm{M}\left(\mathrm{f}^{2} \mathrm{x}, \mathrm{gy}\right)\right), 1,1, \mathrm{~F}\left(\mathrm{M}\left(\mathrm{f}^{2} \mathrm{x}, \mathrm{Sy}\right)\right),\right.
$$


$\geq \mathrm{g}\{\mathrm{F}(\mathrm{M}(\mathrm{Tf} x$, Sy $)), 1,1, \mathrm{~F}(\mathrm{M}(\mathrm{Tf} x$, Sy $))$,

$\mathrm{F}(\mathrm{M}(\mathrm{Sy}, \mathrm{Tfx}))\}$.

By $\left(\mathrm{g}_{1}\right)$ and $\left(\mathrm{g}_{2}\right)$, we have, $\mathrm{m}(\mathrm{x}, \mathrm{y}, \mathrm{t})=1$, using this (2.9) gives

$\int_{0}^{\mathrm{F}(M(\mathrm{Tfx}, \mathrm{Sy}, \mathrm{t}))} \phi(\mathrm{s}) \mathrm{ds} \geq 0$, implies that $\mathrm{M}(\mathrm{Tfx}, \mathrm{Sy}, \mathrm{t})=1$, further implies that $M\left(f^{2} x, f x, t\right)=1$,

Which is a contradiction, hence our claim follows i.e., $\mathrm{fx}=$ $\mathrm{f}^{2} \mathrm{x}$, in the similar fashion, we can prove $\mathrm{gy}=\mathrm{gy}^{2}$. Hence $\mathrm{fx}$ is common fixed point of $\mathrm{f}, \mathrm{g}, \mathrm{T}$ and $\mathrm{S}$ and uniqueness follows easily from (1).

A control function $\Phi:[0,1] \rightarrow[0,1]$ is continuous, monotonically increasing function that satisfies $\Phi(2 \mathrm{t}) \geq$ $2 \Phi(\mathrm{t})$ and $\Phi(1)=1$ if and only if $\mathrm{t}=1$.

Let $\psi: \mathrm{R}^{+} \rightarrow \mathrm{R}^{+}$be such that $\psi(\mathrm{t})>\mathrm{t}$, for each $\mathrm{t} \in(0,1)$.

Theorem 2.5 Let $f$, $g$ be self mapping of a symmetric GVfuzzy metric space $(\mathrm{X}, \mathrm{M}, *)$ and $\mathrm{T}, \mathrm{S}$ be mappings from $\mathrm{X}$ into $\mathrm{B}(\mathrm{X})$ such that the pairs $\{\mathrm{f}, \mathrm{T}\}$ and $\{\mathrm{g}, \mathrm{S}\}$ are occasionally weakly compatible, satisfying

(11)

$$
\int_{0}^{\mathrm{F}(\Phi(\mathrm{M}(\mathrm{Tx}, \mathrm{Sy}, \mathrm{t})))} \phi(\mathrm{s}) \mathrm{ds} \geq \int_{0}^{\psi\left(\mathrm{F}\left(\mathrm{m}_{\Phi}(\mathrm{x}, \mathrm{y}, \mathrm{t})\right)\right)} \phi(\mathrm{s}) \mathrm{d} \mathrm{s}
$$

for each $\mathrm{x}, \mathrm{y} \in \mathrm{X}$, for which $\mathrm{fx} \neq \mathrm{gy}$, where

(12) $\mathrm{m}_{\Phi}(\mathrm{x}, \mathrm{y}, \mathrm{t})=\min \{\mathrm{F}(\Phi(\mathrm{M}(\mathrm{f} x, \mathrm{gy}, \mathrm{t})))$,

$$
\begin{array}{r}
\mathrm{F}(\Phi(\mathrm{M}(\mathrm{fx}, \mathrm{Tx}, \mathrm{t}))), \mathrm{F}(\Phi(\mathrm{M}(\mathrm{gy}, \mathrm{Sy}, \mathrm{t}))), \\
\Phi[(\mathrm{M}(\mathrm{fx}, \mathrm{Sy}, \mathrm{t}) * \mathrm{M}(\mathrm{gy}, \mathrm{Tx}, \mathrm{t})]\}
\end{array}
$$

where $0<\mathrm{p}<1$, then $\mathrm{f}$, $\mathrm{g}$, $\mathrm{T}$ and $\mathrm{S}$ have a unique common fixed point.

Proof - Since the pairs $\{\mathrm{f}, \mathrm{T}\}$ and $\{\mathrm{g}, \mathrm{S}\}$ are occasionally weakly compatible, therefore by definition, there exist $\mathrm{x}, \mathrm{y}$ in $\mathrm{X}$ such that $\mathrm{fx} \in \mathrm{Tx}$, gy $\in \mathrm{Sy}, \mathrm{fTx} \subseteq \mathrm{Tfx}$ and gSy $\subseteq$ Sgy. Also $M(f x, g y, t) \leq M(T x, S y, t)$.

(13) $\mathrm{m}_{\Phi}(\mathrm{x}, \mathrm{y}, \mathrm{t})=\max \left\{\mathrm{F}(\Phi(\mathrm{M}(\mathrm{fx}, \mathrm{gy}, \mathrm{t}))), 1,1, \frac{1}{2}\right.$

$$
[\Phi(2(\mathrm{M}(\mathrm{Tx}, \mathrm{Sy}, \mathrm{t})))]\}
$$

$$
\geq \Phi(\mathrm{M}(\mathrm{Tx}, \mathrm{Sy}, \mathrm{t}))
$$

First, we show that gy $=\mathrm{fx}$. Suppose not, and then by (11) and (13), we have

$$
\begin{aligned}
\int_{0}^{\mathrm{F}(\Phi(\mathrm{M}(\mathrm{Tx}, \mathrm{Sy}, \mathrm{t})))} \phi(\mathrm{s}) \mathrm{ds} & \geq \int_{0}^{\psi\left(\mathrm{F}\left(\mathrm{m}_{\Phi}(\mathrm{x}, \mathrm{y}, \mathrm{t})\right)\right)} \phi(\mathrm{s}) \mathrm{ds} \\
& \geq \int_{0}^{\psi(\mathrm{F}(\Phi(\mathrm{M}(\mathrm{Tx}, \mathrm{Sy}, \mathrm{t})))} \phi(\mathrm{s}) \mathrm{ds} \\
& >\int_{0}^{\mathrm{F}(\Phi(\mathrm{M}(\mathrm{Tx}, \mathrm{Sy}, \mathrm{t})))} \phi(\mathrm{s}) \mathrm{ds}
\end{aligned}
$$

It leads to contradiction, therefore $\mathrm{M}(\mathrm{Tx}, \mathrm{Sy}, \mathrm{t})=1$, which further implies that $M(f x, g y, t)=1$ i.e., $f x=g y$. Hence the claim follows. Also, $M\left(f x, f^{2} x, t\right) \leq M(T f x$, Sy, $t)$. Next we claim that, $f x=f^{2} x$ if not, then by (12), we obtain

$$
\text { (14) } \mathrm{M}_{\Phi}(\mathrm{fx}, \mathrm{y}, \mathrm{t})=\max \left\{\Phi\left(\mathrm{M}\left(\mathrm{f}^{2} \mathrm{x}, \mathrm{gy}, \mathrm{t}\right)\right), 1,1, \frac{1}{2}\right.
$$

$$
\geq \Phi(\mathrm{M}(\mathrm{Tfx}, \mathrm{Sy}, \mathrm{t}))
$$

Next we claim that, $f x=f^{2} x$ if not, then by (11) and (14), we have

$$
\begin{gathered}
\int_{0}^{\mathrm{F}(\Phi(\mathrm{M}(\mathrm{Tfx}, \mathrm{Sy}, \mathrm{t})))} \phi(\mathrm{s}) \mathrm{d} \mathrm{s} \geq \int_{0}^{\psi\left(\mathrm{F}\left(\mathrm{m}_{\Phi}(\mathrm{fx}, \mathrm{y}, \mathrm{t})\right)\right)} \phi(\mathrm{s}) \mathrm{d} \mathrm{s} \\
\quad \geq \int_{0}^{\psi(\mathrm{F}(\Phi(\mathrm{M}(\mathrm{Tfx}, \mathrm{Sy}, \mathrm{t}))))} \phi(\mathrm{s}) \mathrm{d} \mathrm{s} \\
\geq \int_{0}^{\mathrm{F}(\Phi(\mathrm{M}(\mathrm{Tfx}, \mathrm{Sy}, \mathrm{t})))} \phi(\mathrm{s}) \mathrm{d} \mathrm{s}
\end{gathered}
$$

Again, we approaches to contradiction, therefore $\mathrm{M}(\mathrm{Tfx}, \mathrm{Sy}$, $\mathrm{t})=0$, further implies that $\mathrm{M}\left(\mathrm{f}^{2} \mathrm{x}, \mathrm{fx}, 1\right)=1$, hence our claim follows i.e., $f x=f^{2} x$, in the similar fashion, we can prove $g y$ $=\mathrm{gy}^{2}$. Hence $\mathrm{fx}$ is common fixed point of $\mathrm{f}, \mathrm{g}, \mathrm{T}$ and $\mathrm{S}$. Uniqueness follows easily from (11).

Set $\mathrm{G}=\{\Psi:[0, \infty) \rightarrow[0, \infty) ; \Psi$ is a continuous and decreasing mapping with $\Psi(\mathrm{t})=1$ iff $\mathrm{t}=1$ \}

Theorem 2.6 Let $\mathrm{f}$, $\mathrm{g}$ be self mapping of a symmetric GVfuzzy metric space $(\mathrm{X}, \mathrm{M}, *)$ and $\mathrm{T}, \mathrm{S}$ be mappings from $\mathrm{X}$ into $B(X)$ such that the pairs $\{f, T\}$ and $\{g, S\}$ are occasionally weakly compatible, satisfying

$$
\begin{aligned}
\text { (15) } \int_{0}^{\psi(M(T x, S y, t))} \phi(s) d s & \\
& \int_{0}^{\psi(M(f x, g y, t))+\Phi(M(f x, g y, t))} \phi(s) d s
\end{aligned}
$$

for every $x, y \in X$, for which right hand side of (15) is not equal to 0 , where $\psi, \Phi \in \mathrm{G}$, then $\mathrm{f}, \mathrm{g}, \mathrm{T}$ and $\mathrm{S}$ have a unique common fixed point.

Proof - Since the pairs $\{\mathrm{f}, \mathrm{T}\}$ and $\{\mathrm{g}, \mathrm{S}\}$ are occasionally weakly compatible, therefore by definition, there exist $\mathrm{x}, \mathrm{y}$ in $\mathrm{X}$ such that $\mathrm{fx} \in \mathrm{Tx}$, gy $\in \mathrm{Sy}, \mathrm{fTx} \subseteq \mathrm{Tfx}$ and gSy $\subseteq$ Sgy. Also $M(f x, g y, t) \geq M(T x, S y, t)$. First, we show that $g y=f x$. Suppose not, then by (15), we have

$$
\begin{aligned}
\int_{0}^{\psi(M(T x, S y, t))} \phi(s) d s & \geq \int_{0}^{\psi(M(f x, g y, t))+\Phi(M(f x, g y, t))} \phi(s) s \\
& \geq \int_{0}^{\psi(M(T x, S y, t))+\Phi M(T x, S y, t))} \phi(s) d s
\end{aligned}
$$

This leads to contradiction. Therefore $f x=g y$. Hence the claim follows. Again, $M\left(f^{2} x, f x, t\right) \geq M(T f x, S y, t)$, now we claim that $f^{2} x=f x$, if not, the condition (2.15) implies that

$$
\begin{aligned}
\int_{0}^{\psi(M(T f x, S y, t))} \phi(s) d s & \geq \\
& \int_{0}^{\psi\left(M\left(f^{2} x, g y, t\right)\right)+\Phi\left(M\left(f^{2} x, g y, t\right)\right)} \phi(s) d s \\
= & \int_{0}^{\psi\left(M\left(f^{2} x, f x, t\right)\right)+\Phi\left(M\left(f^{2} x, f x, t\right)\right)} \phi(s) d s \\
\geq & \int_{0}^{\psi(M(T f x, S y, t))+\Phi(M(T f x, S y, t))} \phi(s) d s
\end{aligned}
$$

which is a contradiction, and hence the claim follows. On the similar account, it can be proved that $g y=g^{2} y$. Hence $f x$ is common fixed point of $\mathrm{f}, \mathrm{g}, \mathrm{T}$ and $\mathrm{S}$. Uniqueness follows easily from (15).

Example 2.7 Let $X=\{a, b, c\}$. For $t>0$, we define $M: X^{2}$ $\times(0, \infty) \rightarrow(0,1]$ by 


$$
\begin{aligned}
M(a, a, t) & =M(b, b, t)=d(c, c, t)=1, \\
M(a, b, t) & =d(b, a, t)=b, \\
M(a, c, t) & =M(c, a, t)=e,(\text { with } e<b+a) \\
M(b, c, t) & =d(c, b, t)=a,
\end{aligned}
$$

Obviously, $\mathrm{M}$ is symmetric GV-fuzzy metric but not fuzzy metric on $\mathrm{X}$.

We define $\mathrm{T}, \mathrm{S}: \mathrm{X} \rightarrow \mathrm{B}(\mathrm{X})$ by

$$
\begin{aligned}
T(a) & =\{a, c\}, T(b)=\{a, b, c\}, \\
T(c) & =\{a, c\}, S(a)=\{a, b\}, S(b)=\{a, c\}, \\
S(c) & =\{b, c\},
\end{aligned}
$$

And $\mathrm{f}, \mathrm{g}: \mathrm{X} \rightarrow \mathrm{X}$ as follows:

$$
\begin{array}{ll}
\mathrm{f}(\mathrm{a})=\mathrm{a}, & \mathrm{f}(\mathrm{b})=\mathrm{c}, \quad \mathrm{f}(\mathrm{c})=\mathrm{a}, \\
\mathrm{g}(\mathrm{a})=\mathrm{a}, & \mathrm{g}(\mathrm{b})=\mathrm{a}, \quad \mathrm{g}(\mathrm{c})=\mathrm{b},
\end{array}
$$

Now, it is obvious $\mathrm{f}(\mathrm{a}) \in \mathrm{T}(\mathrm{a})$ but $\mathrm{fT}(\mathrm{a}) \neq \mathrm{Tf}(\mathrm{a})$, and $\mathrm{f}(\mathrm{c}) \in$ $\mathrm{T}(\mathrm{c})$ but $\mathrm{fT}(\mathrm{c}) \neq \mathrm{Tf}(\mathrm{c})$, therefore $\{\mathrm{f}, \mathrm{T}\}$ is not weakly compatible. On the other hand, $f(b) \in T(b)$ but $f T(b)=T f(b)$. Hence $\{f, T\}$ is occasionally weakly compatible. Also, g(a) $\in$ $\mathrm{S}(\mathrm{a})$ but $\mathrm{gS}(\mathrm{a}) \neq \mathrm{Sg}(\mathrm{a})$, and $\mathrm{g}(\mathrm{c}) \in \mathrm{S}(\mathrm{c})$ but $\mathrm{gS}(\mathrm{c}) \neq \mathrm{Sf}(\mathrm{c})$, therefore $\{\mathrm{g}, \mathrm{S}\}$ is not weakly compatible. On the other hand, $\mathrm{g}(\mathrm{b}) \in \mathrm{S}(\mathrm{b})$ but $\mathrm{gS}(\mathrm{b})=\mathrm{Sg}(\mathrm{b})$. Hence $\{\mathrm{g}, \mathrm{S}\}$ is occasionally weakly compatible. As $f(a)=g(a) \in T(a)$ and $f(a)=g(a) \in$ $\mathrm{S}(\mathrm{a})$, so $\mathrm{a}$ is a unique common fixed point of $\mathrm{f}, \mathrm{g}, \mathrm{T}$ and $\mathrm{S}$.

\section{Remark 2.8}

As integral contractive condition are indeed generalizations of corresponding contractive condition. Every contractive condition of integral type automatically induces the corresponding conractive condition, not including integral, by setting $\phi(s)=1$ over $\mathrm{R}^{+}$.

Weakly compatible are owc but converse is not true, as in above example.

The Class of symmetric fuzzy metric spaces is more general than that of fuzzy metric spaces.

\section{CONCLUSION}

In this paper, common fixed point theorems in GV-fuzzy metric space have been proved using control function and implicit relation function. There are some possible applications of results in real engineering problems like quantum particle physics, image processing, to achieve access optimization in information system, history prediction. In future scope it is an open problem to relax symmetric condition or occasionally weak compatibility by weaker variants.

Question 1: Are the above mentioned theorems true in weak non-Archimedean fuzzy metric space or in generalized menger spaces.

\section{ACKNOWLEDGEMENT}

The first author is gratefully acknowledged to Council of Scientific and Industrial Research, Government of India, for providing financial assistant under research project no25(0197)/11/EMR-II.

\section{REFERENCES}

[1] Zadeh, L. A. 1965. Fuzzy Sets. Inf. and Cont.18 (1965), 338-353.

[2] Kaleva, O. and Seikkala, S. On fuzzy metric spaces. Fuzzy Sets Syst. 12 (1984), 215-229.

[3] Kramosil, I. and Michalek, J. 1975. Fuzzy metrics and statistical metric spaces, Kybernetika, 15 (1975) 326334.

[4] George. A. and Veeramani, P. 1994. On some results on fuzzy metric spaces. Fuzzy Sets Syst. 64 (1994), 395399.

[5] Schweizer, B. and Sklar, A. 1983. Probabilistic Metric Spaces. North Holland, New York, 1983.

[6] Grabiec, M. 1988. Fixed points in fuzzy metric spaces. Fuzzy Sets Syst. 27 (1988), 385-389.

[7] Subrahmanyam, P. V. 1995. Common fixed point theorem in fuzzy metric spaces. Inf. Sci. 83(4) (1995), 109-112.

[8] Menger, K. 1942, Statistical metric, Proc. Nat. Acad. Sci. 28 (1942), 535-537.

[9] Gregori, V., Morillas, A. and Sapena, A. 2010. Examples of fuzzy metrics and application. Fuzzy Sets Syst. (2010).

[10] Gregory, V. and Romaguera, S. 2004. Characterizing completable fuzzy metric spaces. Fuzzy Sets Syst. 144 (2004), 411-420.

[11] Deng, Z. 1982. Fuzzy pseudo-metric space. J. Math. Anal. Appl. 86 (1982), 74-95.

[12] Erceg, M. A. 1979. Metric space in fuzzy set theory. J. Math. Anal. Appl. 69 (1979), 205-230.

[13] Mishra, S. N., Sharma, N. and Singh, S. L. 1994. Common fixed points of maps on fuzzy metric space. Int. J. Math. Math. Sci. 17(1994), 253-258.

[14] Jungck, G. and Rhoades, B. E. 2006. Fixed point theorems for occasionally weakly compatible Mappings. Fixed Point Theory. 7 (2006), 287-296.

[15] Dibari, C. and Vetro, C. 2003. Fixed point theorem for a family of mapping for fuzzy metric space. Rendi. Cir. Math. Di Palermo. 2 (2003), 315-321.

[16] Rana, R., Dimari, R. C. and Tomar, A. 2010. Fixed point theorem in fuzzy metric space using implicit relation. Int. J. of Comp. Appl. 8(2010), 8887-8875.

[17] Rao, K. P. R., Ravi Babu, G. and Fisher, B. 2008. Common fixed point theorem in fuzzy metric space under implicit relations. Hacet. J. of Math. and Sta. 37 (2008), 97-106. 
[18] Singh, B. and Chauhan, M. S. 2000. Common fixed point of compatible maps in fuzzy metric spaces. Fuzzy Sets and Syst. 115 (2000) 47- 475.

[19Altun, I. and Turkoglu, D. 2008. Some fixed point theorem in fuzzy metric space with implicit relation, Commun. Korean. Math. Soc., Comp. Appl. 23(2008), 111-124.
[20] Branciary, A. 2002. A fixed point theorem for mapping satisfying a general contractive condition of integral type. Int. J. M. and M. Sci. 29 (2002), 531- 536. 